ценка клинической эффективности топической комбинированной терапии больных Экземой, осложненной бактериальной инфекцией

В.А. Охлопков ${ }^{1}$, Е.Ю. Зубарева ${ }^{1}$, Ю.А. Новиков ${ }^{1}$, М.С. Сукач${ }^{1}$, Т.В. Репина² ${ }^{2}$ И.Ю. Лекавичус ${ }^{2}$, Н.В. Гранкина ${ }^{2}$

1 ГБОУ ВПО «Омская государственная медицинская академия» Минздрава России 644043 , г. Омск, ул. Ленина, 12

${ }^{2}$ БУЗ 00 «Клинический кожно-венерологический диспансер»

644001 , г. Омск, ул. 5-я Линия, 117 А

Цель. Оценить эффрективность и переносимость топической терапии больных экземой, осложненной бактериальной инсекцией, комбинированным препаратом мупироцина и бетаметазона дипропионата.

Материал и методы. 22 больных экземой, осложненной бактериальной инфекцией, получали терапию комбинированным препаратом мупироцина и бетаметазона дипропионата в форме мази для наружного применения 2 раза в день на протяжении 14 дней. Клиническую эффрективность оценивали по снижению индекса EASI и дерматологического индекса шкалы симптомов (ДИШС).

Результаты. Клиническое излечение достигнуто у всех пациентов к 14-му дню терапии. Отмечено статистически достоверное снижение индексов EASI и ДИШС. Отмечалась хорошая переносимость препарата.

Заключение. Показаны клиническая эффективность и хорошая переносимость топической комбинированной терапии больных экземой, осложненной бактериальной инфекцией, комбинированным препаратом мупироцина и бетаметазона дипропионата.

Ключевые слова: экзема, Staphylococcus aureus, иммунный ответ, мупироцин, бетаметазона дипропионат, эффективность. 


\section{Estimation of clinical efficiency of topical combination therapy patients with pyoderma complicated eczema}

V.A. Okhlopkov', E.Yu. Zubareva', Yu.A. Novikov ${ }^{1}$, M.S. Sukach ${ }^{1}$, T.V. Repina ${ }^{2}$, I.Yu. Lekavitchus², N.V. Grankina²

${ }^{1}$ Omsk State Medical Academy, chair of Dermatology, venerology and cosmetology Lenina str., 12, Omsk, 644043, Russia

${ }^{2}$ Clinical dermatovenerologic dispensary

5 Line str., 117 A, Omsk, 644001, Russia

The results of direct open-label study of efficacy and portability of combination therapy with topical betamethasone dipropionate and mupirocin are presented.

Material and methods. Twenty two patients with pyoderma complicated eczema were treated with ointment for external use (betamethasone dipropionate and mupirocin) 2 times a day for 14 days. Clinical efficacy was assessed by the reliability decrease of index EASI and dermatological symptoms scale index (DSSI).

Results. Clinical convalescense was achieved in all patients by the 14th day of therapy. There was a statistically significant decrease in the indices EASI, DSSI. Portability were well.

Conclusion. Our study results showed clinical efficacy and portability of topical combination therapy of betamethasone dipropionate and mupirocin in patients with pyoderma complicated eczema.

Key words: eczema, Staphylococcus aureus, immune response, mupirocin, betamethasone dipropionate, efficiency. 
Кожа здоровых людей обладает высокой резистентностью против инвазий огромного количества бактерий. Доказано, что у лиц с хроническими дерматозами, такими как атопический дерматит, экзема, нарушается целостность рогового слоя эпидермиса, снижается фрункция кожного барьера за счет дефицита липидов, обладающих антибактериальными свойствами [1]. Кроме того, на поверхности кожи снижается количество антимикробных пептидов, которые способны проникать в мембрану бактерий, обуславливая их гибель, и активировать иммунный ответ организма. Все эти фракторы способствуют формированию входных ворот для инфицирования кожи [2].

Ведущую роль в возникновении инфекционных заболеваний кожи на фоне генетически детерминированной наследственной предрасположенности играют различные патогенные микроорганизмы, прежде всего Staphylococcus aureus [3]. В состав клеточной оболочки St. aureus входят тейхоевая кислота и различные поверхностные белки, способствующие адгезии микроорганизма на коже в местах хронического воспаления [2]. Бактерии способны индуцировать иммунологические реакции, что приводит к обострению хронических дерматозов [4].

При лечении бактериальных инфекций кожи легкой и средней степени тяжести приоритет отдается топическим антибактериальным средствам, которые обладают широким спектром действия, создают высокие концентрации именно в очагах воспаления и сводят к минимуму риск развития побочных эффректов. Хронические дерматозы, осложненные пиодермией, на начальном этапе лечения требуют назначения комбинированных препаратов, обладающих антибактериальным и противовоспалительным эффектами $[5,6]$.

Современный и принципиально новый топический антибиотик мупироцин имеет природное происхождение, так как получен из культуры Pseudomonas fluorescens. Антибактериальное действие мупироцина связано с ингибированием фрермента изолейцил-гPHКсинтетазы, в результате чего нарушается синтез не только антибактериальных белков, но также РНК. Фармакологические способности мупироцина обеспечивать высокие местные концентрации действующего вещества обуславливают его бактерицидное действие в отношении большинства бактериальных агентов [3, 7].

Основное клиническое значение мупироцина заключается в действии на большинство штаммов стафилококков, в том числе MRSA, а также штаммов, устойчивых к другим антимикробным препаратам. Отличительной особенностью мупироцина является низкая in vitro активность в отношении представителей нормальной микрофрлоры кожи (Microccocus spp., Corynebacterium spp., Propionibacterium spp.), которая является естественным защитным барьером организма [8-11]. По своей эфффективности мупироцин при топи- ческом применении не уступает ряду системных антибактериальных средств (эритромицину, ампициллину, цефралексину) [12]. Резистентность микроорганизмов к мупироцину развивается редко, и перекрестной устойчивости препарата с другими антимикробными препаратами не возникает, что связывают с уникальным механизмом его действия [13, 14].

Комбинация мупироцина и высокоэффрективного топического кортикостероида бетаметазона дипропионата позволяет использовать данное комбинированное топическое средство при аллергодерматозах, осложненных пиококковой инфекцией. Местное применение препарата обеспечивает достижение высокой его концентрации в очаге развития инфекции при низкой системной биодоступности и высокой безопасности [7]. Клиническая эффрективность мази для наружного применения Супироцин-Б, содержащей мупироцин и бетаметазона дипропионат, при инфицированных дерматозах оценивается примерно в 95\% [15].

Целью прямого открытого исследования, проведенного кафедрой дерматовенерологии и косметологии ГБОУ ВПО ОмГМА Минздрава России на клинической базе ГБУЗ ОО «ККВД», явилась оценка клинической эффективности и переносимости, топической терапии больных экземой средней степени тяжести, осложненной бактериальной инфекцией, комбинированным препаратом, содержащим мупироцин и бетаметазона дипропионат.

\section{Материал и методы}

В исследование были включены 22 пациента (12 женщин и 10 мужчин) в возрасте от 18 до 65 лет с клинически установленным диагнозом экземы средней степени тяжести, осложненной бактериальной инфрекцией. Критерии исключения из исследования: беременность, лактация, повышенная чувствительность к компонентам препарата, участие в другом клиническом исследовании.

На каждого больного заполнялась индивидуальная регистрационная карта и велась фротодокументация при каждом визите к врачу (протокол клинического исследования одобрен этическим комитетом ГБОУ ВПО ОмГМА Минздрава России от 19 декабря 2011 г.). Распространенность и степень тяжести экзематозного процесса, а также эффективность проводимой терапии оценивали путем расчета индекса EASI и дерматологического индекса шкалы симптомов (ДИШС).

До начала терапии у всех больных, включенных в клиническое исследование, патологический процесс носил симметричный, локализованный характер (занимал не более 3 анатомических областей). Высыпания были представлены располагавшимися на фоне пастозности, гиперемии и инфильтрации без четких границ везикулами, пустулами, эрозиями с точечным мокнутием («серозные колодцы»), а также серозными, геморрагическими и импетигинозными корочками. 
Субъективно все больные отмечали умеренные болезненность и зуд в местах локализации патологического процесса. Данная клиническая картина соответствовала средней степени тяжести экземы, осложненной бактериальной инфекцией.

Всем пациентам назначалась мазь для наружного применения Супироцин-Б 2 раза в день на протяжении 14 дней. Кроме того, больные получали стандартную гипосенсибилизирующую терапию (глюконат кальция $10 \%-5$ мл в/м 1 раз в день в течение 5 дней; левоцетиризина дигидрохлорид 5 мг 1 раз в день в течение 3-5 дней).

Оценку клинической эффрективности терапии проводили на 3, 7 и 14-й дни лечения. Переносимость терапии оценивали по частоте возникновения нежелательных явлений.

Статистическая обработка данных проводилась с помощью программы MedCalc. Для статистического анализа использовали критерий Манна - Уитни. Данные представляли в виде средней арифметической величины и стандартного отклонения от нее.

\section{Результаты}

Перед началом лечения индекс EASI у больных составил $35 \pm 0,4$, индекс ДИШС $-16 \pm 0,2$. На фроне проводимой терапии у всех пациентов $(n=22)$ к 3-му дню лечения отмечалось уменьшение отека, прекращение экссудации, отсутствие новых высыпаний, субъектив- но - уменьшение болезненности, зуда. К 7-му дню терапии индекс EASI уменьшился до $23 \pm 0,3$ ( $p<0,001)$, а ДИшС - до $7 \pm 0,2(p<0,001)$. К моменту окончания терапии (14-й день) значение индекса EASI уменьшилось в 5,83 раза $(6 \pm 0,2)(p<0,001)$, а величина индекса ДИШС в 5,33 раза $(3 \pm 0,2),(p<0,001)$ по сравнению с исходным значением (рис. 1,2$)$. У всех больных $(n=22)$ на 14-й день терапии достигнуто клиническое выздоровление (рис. 3, 4.).

На фоне терапии новых высыпаний у пациентов не отмечалось. Неблагоприятных побочных реакций выявлено не было.

Все пациенты по окончании лечения приняли участие в анонимном анкетном опросе. Данные опроса свидетельствуют, что 95,5\% ( $n=21)$ больных отметили уменьшение субъективных ощущений уже с 3-го дня терапии, $100 \%(n=22)$ больных считают, что мазь Супироцин-Б не обладает запахом и не оставляет пятен на одежде, легко наносится и смывается при необходимости; 86,4\% ( $n=19)$ больных предпочтут использовать топический комбинированный препарат в фрорме мази при возможных последующих рецидивах дерматоза.

\section{Обсуждение}

При экземе происходит нарушение микробиоценоза кожи в сторону повышенной колонизации патогенной микрофрлоры, что приводит к нарастанию сенсибилизации и усилению иммунного ответа. Сочетание

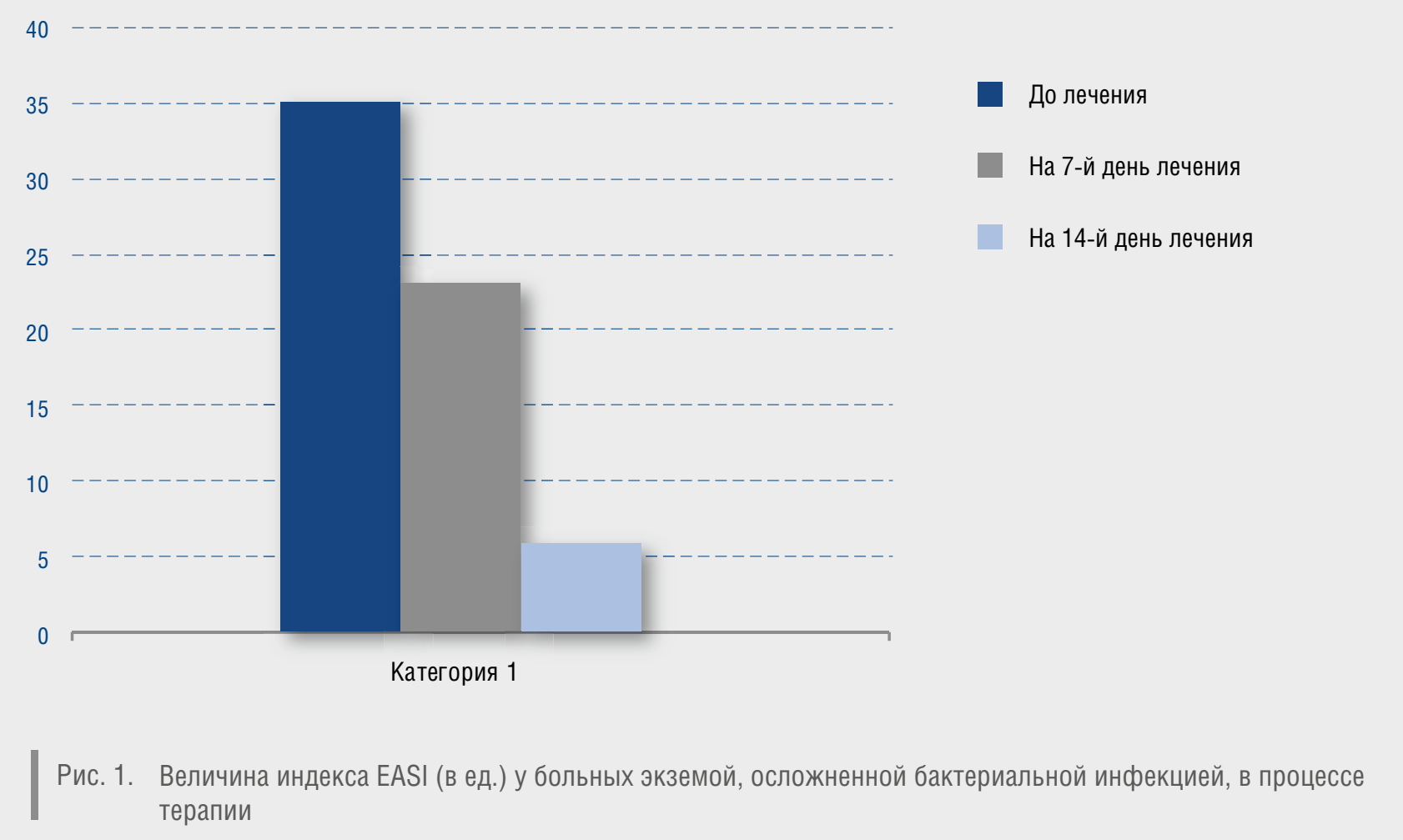




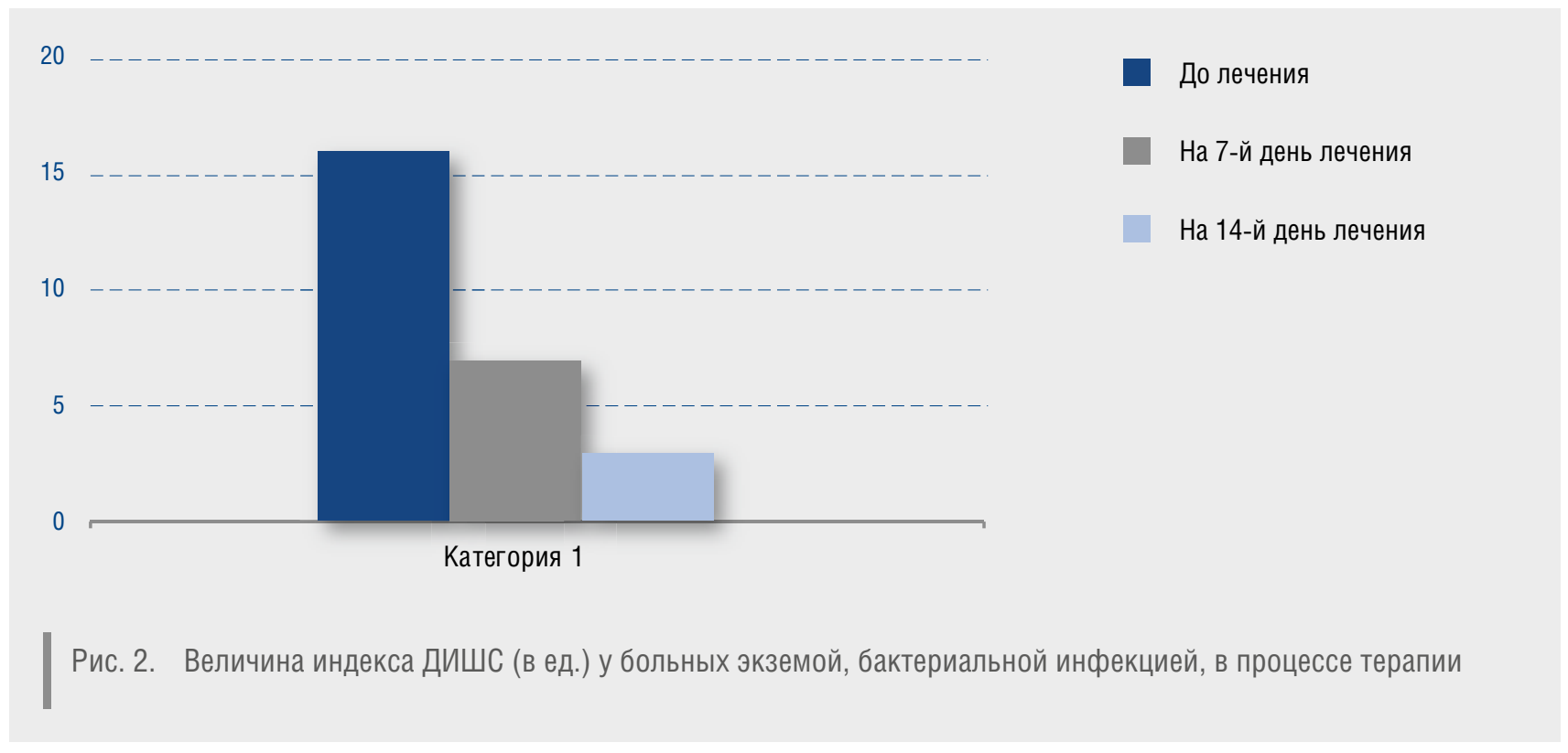

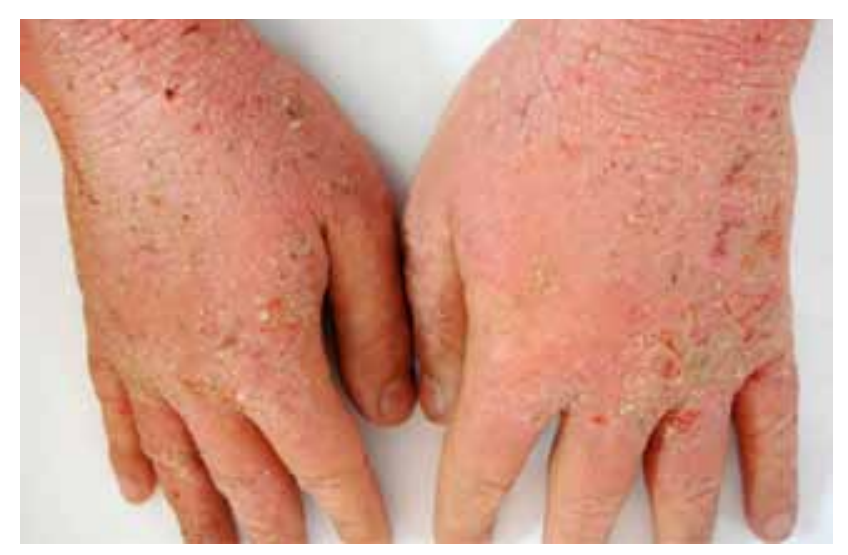

a

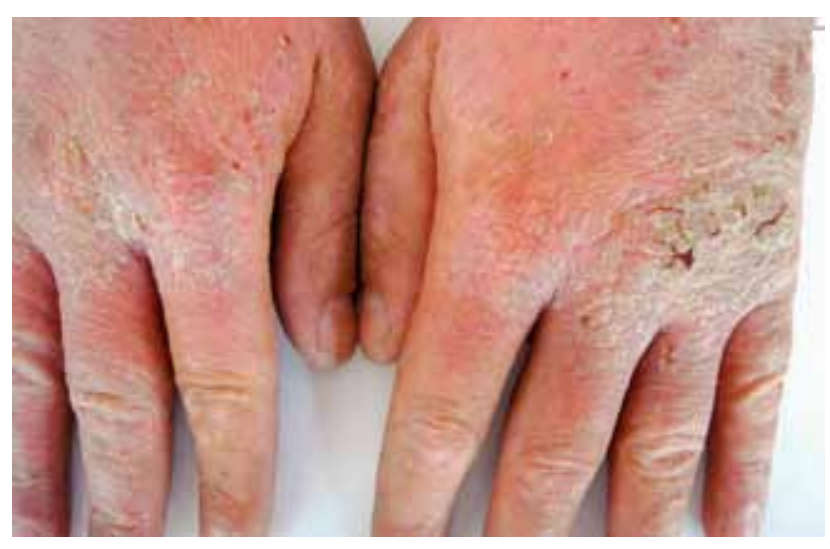

б

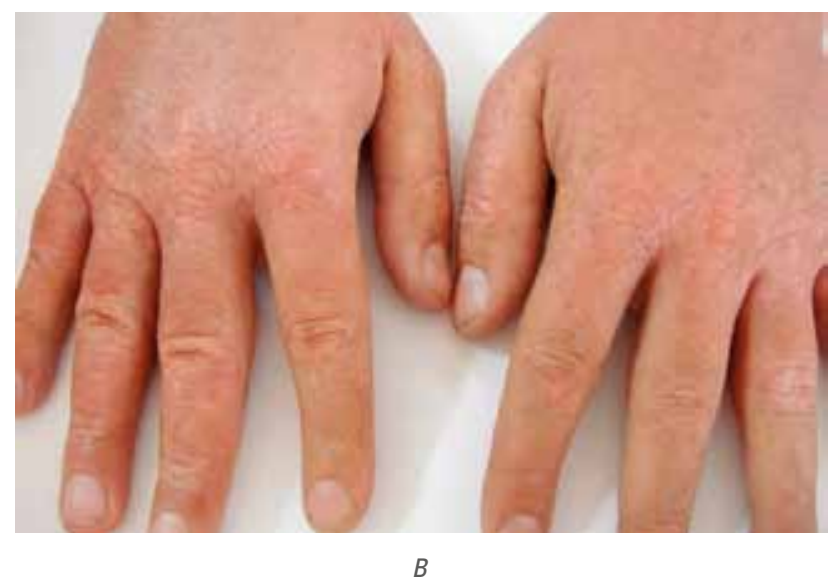

Рис. 3. Больной М. Хроническая экзема кистей, осложненная бактериальной инфекцией: до лечения (а), на 7-й день лечения (б) и на 14-й день лечения (в) 


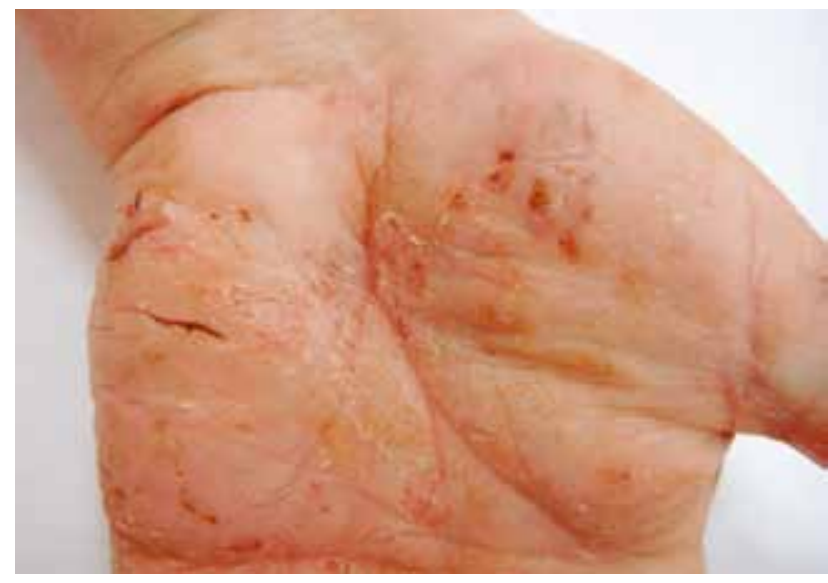

a

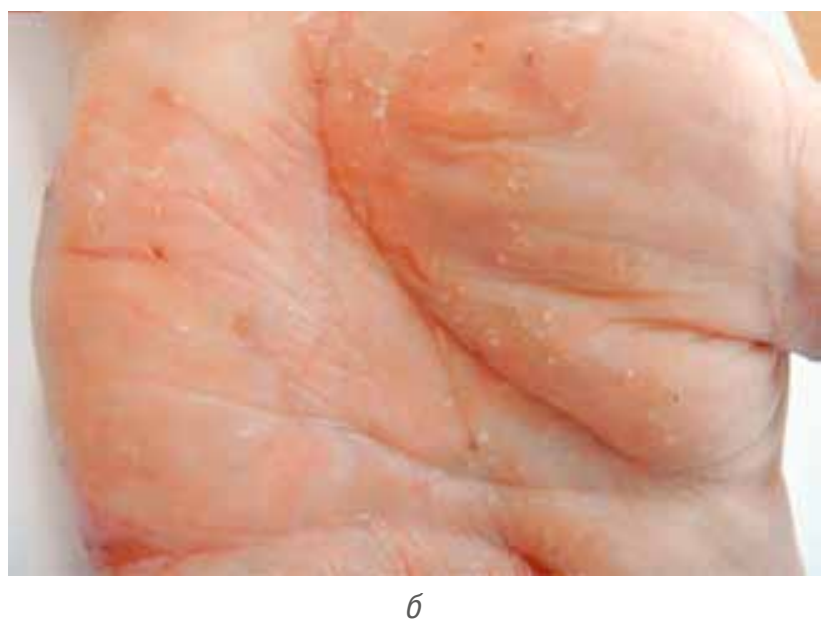

$\sigma$

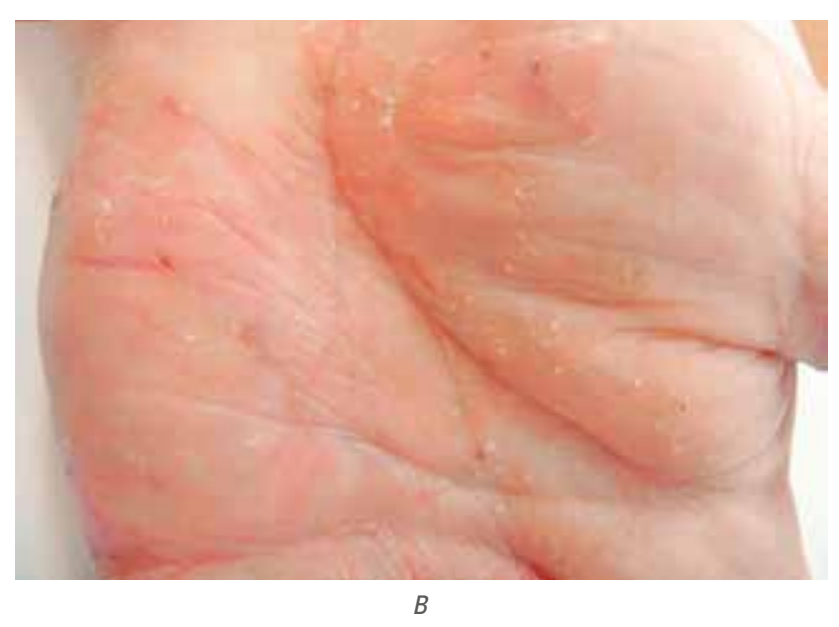

Рис. 4. Больной К. Хроническая экзема кистей, осложненная бактериальной инфрекцией: до лечения (a), на 7-й день лечения (б) и на 14-й день лечения (в)

современной антибактериальной и противовоспалительной терапии, представленной в фрорме мази для наружного применения, является приоритетным направлением лечения больных экземой, осложненной пиодермией. Выполненное простое открытое исследование показало клиническую эффективность топической терапии больных экземой средней степени тяжести, осложненной бактериальной инфекцией, комбинированным препаратом мупироцина и бетаметазона дипропионата. Уже на 3-й день все пациенты $(n=22)$ отметили положительный эффект от проводимой терапии, который в дальнейшем привел к статистически достоверному снижению индексов EASI, ДИСШ и клиническому выздоровлению в виде регресса патологических высыпаний и исчезновению субъективных ощущений. Отсутствие нежелательных явлений свидетельствует о хорошей переносимости топического комбинированного средства. Данные анонимного анкетного опроса, проведенного в конце исследования, говорят о быстром регрессе воспаления и хороших органолептических свойствах препарата. Полученные нами результаты согласуются с результатами выполненных ранее исследований эффективности топической комбинированной терапии больных экземой, осложненной бактериальной инфекцией, мупироцином и бетаметазона дипропионатом [3, 7].

\section{Заключение}

Согласно данным, полученным в проведенном прямом открытом исследовании, комбинированный препарат мупироцина и бетаметазона дипропионата в форме мази для наружного применения обладает доказанным антибактериальным и противовоспалительным действием и эффрективен при лечении хронической экземы, осложненной бактериальной инфекцией. Препарат характеризуется хорошей переносимостью у больных и отсутствием нежелательных явлений. І 


\section{Литература}

1. Izadpanah A., Gallo R.L. Antimicrobial peptides. J Am Acad Dermatol 2005; 52 (3Pt1): 381-390.

2. Wolff K., Goldsmith L.A., Katz S.I. et al. Fitzpatrick's dermatology in general medicine: $v 3 \mathrm{t}$. Per. s angl.; obshch. red. akad. A.A. Kubanovoy. M.: Izd-vo Panfilova; BINOM, Laboratoriya znaniy, 2012; T.3: s. 1841-1847. [Вольф К., Голдсмит Л.А., Кац С.И. и др. Дерматология Фицпатрика в клинической практике; в 3 т. Пер. с англ.; общ. ред. акад. А.А. Кубановой. М.: Издво Панфилова; БИНОМ, Лаборатория знаний, 2012; T. 3. C. 1841-1847.]

3. Bakulev A.L., Kravchenya S.S., Murashkin N.N. et al. Microbial eczema: new potential of combined topical treatment. Vestn Dermatol Venerol 2011; 6: 98-104 [Бакулев А.Л., Кравченя С.С., Мурашкин Н.Н. и др. Микробная экзема: новые возможности комбинированной топической терапии. Вестн дерматол и венерол 2011; (6): 98-104.]

4. Sohn A., Francel A., Patel R.V., Goldenberg G. Eczema. Mt Sinai J Med 2011; 78 (5): 730—739.

5. Chang C., Keen C.L., Gersbwin M.E. Treatment of eczema. Clin Rev Allergy Immunol. 2007; 35 (3): 204-225.
6. Hoare C., Li Wan Po A., Williams H. Systemic review of treatments for atopic eczema. Health Technol Assess 2000; 4 (37): 1—191.

7. Okovityy S.V., Ivkin D.Yu. Mupirotsin: klinicheskoe primenenie. Consilium medicum 2011; (4): 3-10. [Оковитый С.В., Ивкин Д.Ю. Мупироцин: клиническое применение. Consilium medicum 2011; (4): 3-10.]

8. Sutherland R., Boon R.J., Griffin K.E. et al. Antibacterial activity of mupirocin (pseudomonic acid) a new antibiotic for topical use. Antimicrob Agent Chemother 1985; 27 (4): 495-498.

9. Leyden J.J. Mupirocin - a new topical antibiotic. Semin Dermatol 1987; (6): 48-54.

10. Pappa K.A. The clinical development of mupirocin. J Am Acad Dermatol 1990; 22 (5 Pt 1): 873-879.

11. Bogdanovich T.M., Strachunskiy L.S. Mupirotsin: unikal'nyy antibiotik dlya mestnogo primeneniya. Clinical Microbiology and Antimicrobial Therapy 1999; 1 (1): 57—65 [Богданович T.М., Страчунский Л.С. Мупироцин: уникальный антибиотик для местного применения. Клин микробиол антимикроб химиотер 1999; 1 (1): 57-65.]
12. Prakticheskoe rukovodstvo po antiinfektsionnoy khimioterapii. Pod red L.S.Strachunskogo, Yu.B. Belousova, S.N. Kozlova, M.: NIIAKh SGMA, 2002: 586 S. [Практическое руководство по антиинсекционной химиотерапии. Под ред. Л.С. Страчунского, Ю.Б. Белоусова, С.Н. Козлова, М.: НИИАХ СГМА, 2002: 586 с.]

13. Annigeri R., Conly J., Vas S. at al. Emergence of mupiricin-resistant Staphylococcus aureus in chronic peritoneal dialysis patients using mupirocin prophylaxis to prevent exit-site infection. Perit Dial Int 2001; 21 (6): 554—559.

14. Vas S.I., Conly J., Bargman J.M., OveopouIos D.G. Resistence to mupirocin no indication of it to date while using mupirocin ointment for prevention of Staphylococcus aureus exit-site infections in peritoneal dialysis patients. Perit Dial Int 1999; 19 (4): 313-314.

15. Savant S., Janaki V.R., Mittal R.R. et al. Evaluation of safety and efficacy of supirocin-B (mupirocin 2\% + betamethasone dipropionate $0.05 \%$ in infected dermatosis - a post marketing study. J Indian Med Assoc 2000; 90 (4): 194-195.

об авторах:

В.А. Охлопков - д.м.Н., профессор, заведующий кафедрой дерматовенерологии и косметологии ГБОУ ВПО ОмГМА Минздрава России

Е.Ю. Зубарева — к.М.Н., доцент касредры дерматовенерологии и косметологии ГБОУ ВПО ОмГМА Минздрава России

Ю.А. Новиков - д.М.Н., профеессор, главный врач БУЗ 00 «КВД»

М.С. Сукач — к.м.н., ассистент каффедры дерматовенерологии и косметологии ГБоУ ВПО ОмГМА Минздрава России

Т.В. Репина - к.м.н., заведующая кожным отделением БУЗ 00 «КВД»

И.Ю. Лекавичус — заведующая инфекционным отделением БУЗ 00 «КВД»

Н.В. Гранкина — врач кожного отделения БУЗ 00 «КВД»

Конфликт интересов

Авторы заявляют об отсутствии потенциального конфрликта интересов, требующего раскрытия в данной статье 